\title{
Stability-Indicating HPLC Determination of Gemcitabine in Pharmaceutical Formulations
}

\author{
Rahul Singh, ${ }^{1}$ Ashok K. Shakya, ${ }^{2}$ Rajashri Naik, ${ }^{2}$ and Naeem Shalan ${ }^{2}$ \\ ${ }^{1}$ Faculty of Pharmacy, Integral University, Kursi Road, Lucknow 226-026, India \\ ${ }^{2}$ Faculty of Pharmacy and Medical Sciences, Al-Ahliyya Amman University, P.O. Box 263, Amman 19328, Jordan
}

Correspondence should be addressed to Ashok K. Shakya; ashokkumar2811@gmail.com

Received 28 September 2014; Revised 23 January 2015; Accepted 26 January 2015

Academic Editor: David M. Lubman

Copyright (c) 2015 Rahul Singh et al. This is an open access article distributed under the Creative Commons Attribution License, which permits unrestricted use, distribution, and reproduction in any medium, provided the original work is properly cited.

A simple, sensitive, inexpensive, and rapid stability indicating high performance liquid chromatographic method has been developed for determination of gemcitabine in injectable dosage forms using theophylline as internal standard. Chromatographic separation was achieved on a Phenomenex Luna C-18 column $(250 \mathrm{~mm} \times 4.6 \mathrm{~mm} ; 5 \mu)$ with a mobile phase consisting of $90 \%$ water and $10 \%$ acetonitrile $(\mathrm{pH} 7.00 \pm 0.05)$. The signals of gemcitabine and theophylline were recorded at $275 \mathrm{~nm}$. Calibration curves were linear in the concentration range of $0.5-50 \mu \mathrm{g} / \mathrm{mL}$. The correlation coefficient was 0.999 or higher. The limit of detection and limit of quantitation were 0.1498 and $0.4541 \mu \mathrm{g} / \mathrm{mL}$, respectively. The inter- and intraday precision were less than $2 \%$. Accuracy of the method ranged from $100.2 \%$ to $100.4 \%$. Stability studies indicate that the drug was stable to sunlight and UV light. The drug gives 6 different hydrolytic products under alkaline stress and 3 in acidic condition. Aqueous and oxidative stress conditions also degrade the drug. Degradation was higher in the alkaline condition compared to other stress conditions. The robustness of the methods was evaluated using design of experiments. Validation reveals that the proposed method is specific, accurate, precise, reliable, robust, reproducible, and suitable for the quantitative analysis.

\section{Introduction}

Gemcitabine hydrochloride (Figure 1), (4-amino-1-[(2R, 4R, 5R)-3,3-difluoro-4-hydroxy-5-(hydroxymethyl) oxolan2 -yl] pyrimidin-2-one) is a $\beta$-difluoronucleoside, purine antimetabolite. The drug is an antitumor agent, employed extensively against several human malignancies like ovarian, lung, pancreatic, bladder, urothelial, and breast cancer. It is currently marketed as a lyophilized powder. The drug is also extensively employed as antiviral agent, enzyme inhibitor, immunosuppressive agent, and radiation-sensitizing agents. Gemcitabine is a prodrug that enters the cell by means of nucleoside transporters and becomes active through an intracellular transformation catalyzed by deoxycytidine kinase to its diphosphate and triphosphate derivatives. The triphosphate derivative is incorporated into the DNA strand, inhibiting thymidylate synthetase which inhibits DNA synthesis and chain elongation, contributing to the antineoplastic activity of the drug. The diphosphate derivative inhibits ribonucleotide reductase, the enzyme responsible for catalyzing synthesis of deoxynucleoside-triphosphate required for DNA synthesis. Gemcitabine triphosphate competes with endogenous nucleoside triphosphate for incorporation into DNA [1-3].

A literature survey reveals that only a few methods based on ultraviolet spectroscopy [4], HPTLC [5], and HPLC [613] are available for determination of drug in formulation. Although several HPLC [14-22] and LC-MS/MS [23-28] methods have been reported for estimation of drug and its metabolites in biological fluids, these methods [23-28] are complicated, costly, and time consuming in comparison to a simple HPLC-UV method. A few stability indicating that HPLC methods $[3,11,12]$ have been reported, which provides variable level of degradation of gemcitabine. Jansen et al. [3] reported the separation and identification of degraded product of gemcitabine in acidic stress condition. Mastanamma et al. [11] and Kudikala et al. [12] have reported 


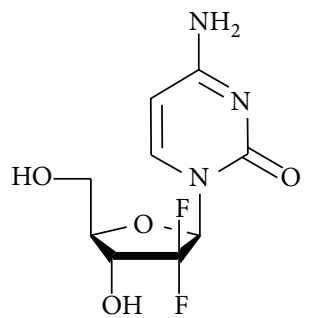<smiles>Cn1c(=O)c2[nH]cnc2n(C)c1=O</smiles>

(2)

(1)

Figure 1: Chemical structures of gemcitabine (1) and theophylline (2).

the validated stability indicating method which can separate the hydrolytic degraded product of gemcitabine. However, to the best of our knowledge none of the HPLC method reported the oxidative degraded product of gemcitabine. Previously published methods for formulation are less robust and need more investigations for method development and validation. Stability-indicating methods have to demonstrate that they are specific, which involves evaluating the drug in the presence of its degradation products [29]. The present investigation describes a simple, rapid, accurate, precise, robust stability indicating RP-HPLC method for the determination of gemcitabine for dosage forms. The robustness of the method was studied using $2^{4}$ factorial design. The method was validated as per the ICH guidelines.

\section{Experimental}

2.1. Chemicals and Reagents. The reference sample of gemcitabine was supplied by M/s Shilpa Medicare Limited, Raichur, India. Theophylline (2) was received as gift sample from Hetero Pharmaceutical Ltd., Hyderabad, India. The marketed formulation of drug (Cytogem, Dr. Reddys, Mumbai, India) was purchased from the local market. All reagents were of analytical grade unless stated otherwise. Reverse osmosis quality water (purified with a Milli-RO plus Milli-Q station Millipore Corp., USA) and HPLC quality water were used throughout. Acetonitrile and methanol were supplied by Panreac (Barcelona, Spain).

2.2. HPLC Instrumentation and Conditions. A Shimadzu Prominence high pressure liquid chromatographic instrument provided with a Luna C-18 column $(250 \mathrm{~mm} \times 4.6 \mathrm{~mm}$; $5 \mu$ ), an LC 20AT-VP solvent delivery system, a universal loop injector (Rheodyne $7725 \mathrm{i}$ ) of injection capacity of $20 \mu \mathrm{L}$, and an SPD 20A UV-visible detector $\left(\lambda_{\max } 275 \mathrm{~nm}\right)$ was employed in the study. Data acquisition was carried out using LC-Solution software. Chromatographic analyses were carried out using the mobile phase of acetonitrilewater $(10: 90 ; \mathrm{pH}$ adjusted to 7.0 using trietylamine and orthophosphoric acid). The mobile phase was prepared daily and filtered through a $0.45 \mu \mathrm{m}$ membrane filter (Millipore Corp., USA). The temperature of column was maintained at $25 \pm 1^{\circ} \mathrm{C}$. Robustness, cross-validation and stability studies were carried out on Shimadzu Prominence Liquid Chromatographic system consists of quaternary gradient pump: Shimadzu-20-AD UFLC; Degasser: DGU-20A3 Prominence Degasser; Autosampler and Injector: SIL-20A Prominence Autosampler; Detector: Diode Array Detector (SPD-M20A); Communication Bus module: CBM-20A; and Column: Luna $\mathrm{C}-18$ column $(250 \mathrm{~mm} \times 4.6 \mathrm{~mm} ; 5 \mu)$. The signals were captured using Windows based LC-Solution software (version $1.25)$.

\subsection{Preparation of Stock and Standards Solutions}

2.3.1. Gemcitabine Standard and Working Solutions. An accurately weighed amount $(100 \mathrm{mg})$ of gemcitabine was transferred into $100 \mathrm{~mL}$ calibrated flask and dissolved in appropriate volume of methanol. Then, the void volume was completed with methanol to produce a stock solution of $1000 \mu \mathrm{g} / \mathrm{mL}$. The stock solution was further diluted with mobile phase to obtain working solutions $(25,100$, and $200 \mu \mathrm{g} / \mathrm{mL})$.

2.3.2. Preparation of the Internal Standard (IS) Solution. An accurately weighed amount $(100 \mathrm{mg})$ of theophylline was transferred into $100 \mathrm{~mL}$ volumetric flask and dissolved in $25 \mathrm{~mL}$ of methanol. The resultant solution was thoroughly sonicated till complete dissolution of the drug has occurred. Volume was made up to the mark with water.

2.3.3. Calibration Standards. Calibration standards were prepared freshly using either stock or intermediate working solution of gemcitabine and internal standard. Standard solution of concentrations $0.5,1.0,2.0,5.0,10,15,25,40$, and $50 \mu \mathrm{g} / \mathrm{mL}$ was prepared. All these solutions were containing $20 \mu \mathrm{g} / \mathrm{mL}$ of theophylline as standards. These solutions were analyzed immediately to avoid degradation.

2.3.4. Quality Control Samples. Similarly, quality control samples of concentration $1,5,20,30$, and $45 \mu \mathrm{g} / \mathrm{mL}$ containing IS $(20 \mu \mathrm{g} / \mathrm{mL})$ were prepared freshly and analyzed.

2.4. Preparation of Sample for Assay. Twelve injection vials containing the drug in the lyophilized powder form of two 
TABLE 1: Linearity data of the proposed method.

\begin{tabular}{|c|c|c|c|c|c|}
\hline Conc. $(\mu \mathrm{g} / \mathrm{mL})$ & Mean peak area (gemcitabine) $(n=6)$ & Mean peak area (IS) & Mean area ratio & Conc. found $(\mu \mathrm{g} / \mathrm{mL})$ & $\%$ assay \\
\hline 0.5 & 11556.2 & 490138.6 & 0.02358 & 0.50 & 99.0 \\
\hline 1.0 & 22196.2 & 527242.0 & 0.04210 & 1.03 & 102.6 \\
\hline 2.0 & 40119.6 & 516202.8 & 0.07772 & 2.05 & 102.3 \\
\hline 5.0 & 99206.8 & 549256.6 & 0.18062 & 4.99 & 99.9 \\
\hline 10.0 & 197702.2 & 546987.8 & 0.36144 & 10.18 & 101.8 \\
\hline 15.0 & 298096.4 & 551610.8 & 0.54041 & 15.30 & 102.0 \\
\hline 25.0 & 496084.0 & 560316.6 & 0.88536 & 25.19 & 100.8 \\
\hline 40.0 & 791722.0 & 566686.4 & 1.39711 & 39.85 & 99.6 \\
\hline 50.0 & 987580.6 & 553478.0 & 1.78432 & 50.95 & 101.9 \\
\hline \multicolumn{6}{|c|}{$y=0.0353 x+0.0063, r^{2}=0.9998$} \\
\hline
\end{tabular}

TABLE 2: Accuracy of the method.

\begin{tabular}{lcccc}
\hline \multirow{2}{*}{ Amount taken $(\mu \mathrm{g} / \mathrm{mL})$} & \multicolumn{2}{c}{ Amount added } & Amount recovered (mean $\pm \mathrm{SD})(n=6)$ & \% recovery (mean \pm SD) \\
& $\%$ & $\mu \mathrm{g} / \mathrm{mL}$ & $25.09 \pm 0.10$ & $100.37 \pm 0.40$ \\
20 & 25 & 5 & $30.06 \pm 0.09$ & $100.19 \pm 0.31$ \\
20 & 50 & 10 & $36.15 \pm 0.21$ & $100.42 \pm 0.59$ \\
20 & 80 & 16 & $40.14 \pm 0.13$ & 0.40 \\
20 & 100 & 20 & $44.07 \pm 0.06$ & 0.59 \\
20 & 120 & 24 & & $100.34 \pm 0.33$ \\
\hline
\end{tabular}

different batches were studied. Their aluminum closures were removed. The vials were weighed with the drug and after removing the content in empty state. With the help of the data available weight of the lyophilized powder was calculated. An accurately weighed portion from this powder equivalent to $10 \mathrm{mg}$ of drug was transferred to $100 \mathrm{~mL}$ calibrated volumetric flask and $10 \mathrm{~mL}$ of internal standard solution was also transferred to it quantitatively. $50 \mathrm{~mL}$ of methanol was added to the flask and the contents of the flask were swirled, sonicated for $5 \mathrm{~min}$, and then completed to volume with water. The prepared solutions were diluted quantitatively with mobile phase to obtain a solution of $20 \mu \mathrm{g} / \mathrm{mL}$ drug and internal standard for the analysis.

\subsection{Analytical Method Validation}

2.5.1. Linearity, Limit of Detection (LOD), and Limit of Quantitation (LOQ). Appropriate volumes of gemcitabine stock standard solution $(1000 \mathrm{mg} / \mathrm{mL})$ were diluted with mobile phase to produce concentrations of $0.5,1.0,2.0,5.0,10$, $15,25,40$, and $50 \mu \mathrm{g} / \mathrm{mL}$. Replicates of each concentration were independently prepared and injected into the chromatograph. Linearity was evaluated by the linear least-squares regression model using weighting factor $x$. Microsoft office excel 2007 was used for statistical analysis. The method was validated according to $\mathrm{ICH}$ guidelines of the validation of analytical methods [29]. A 5\% significance level was used for evaluation. The method was evaluated by determination of the correlation coefficient and intercept values. LOD and LOQ were determined from the best fitted calibration curve. LOD and LOQ were calculated as $3.3 \times \sigma_{n-1} / S$ and $10 \times \sigma_{n-1} / S$, where $\sigma_{n-1}$ is the standard deviation of the intercept and $S$ is the slope of the calibration curve.

2.5.2. Precision. Precision was measured using triplicate determination of quality control samples of $1,5,20,30$, and $45 \mu \mathrm{g} / \mathrm{mL}$ of gemcitabine, on different occasions $(0,3$, and $6 \mathrm{~h}$ ) and different days. The precision (RSD) of the method was determined as intraday precision (repeatability) and intermediate precision. The intermediate precision was estimated from the RSD of the analysis of the samples prepared at the same concentration but on 3 different days at different concentration levels, while intraday precision was calculated by analyzing the same concentration during the same day at different time.

2.5.3. Accuracy. Accuracy of method was determined by addition of known amounts of gemcitabine $(n=3$, at each level of $25,50,80,100$, and $120 \%$ levels) to a sample solution of known concentration (formulation). From these solutions appropriate solution was prepared and analyzed and the total amount recovered was calculated. In this work, the mean recovery of the target concentration was $100 \pm 2 \%$ for acceptance.

2.5.4. Robustness. It is a measure of reproducibility of test results under normal, expected operational condition from analyst to analyst. The robustness of the method was evaluated on the basis of precision, as measured by percent coefficient of variation (RSD), determined as each concentration level was required not to exceed $2 \%$. Design of experiments 
TABLE 3: Precision study of the proposed method.

\begin{tabular}{|c|c|c|c|c|}
\hline \multirow[b]{2}{*}{ Concentration $(\mu \mathrm{g} / \mathrm{mL})$} & \multicolumn{2}{|c|}{ Intraday precision } & \multicolumn{2}{|c|}{ Interday precision } \\
\hline & $\begin{array}{l}\text { Conc. found } \\
\text { Mean } \pm \text { SD }\end{array}$ & RSD & $\begin{array}{l}\text { Conc. found } \\
\text { Mean } \pm \text { SD }\end{array}$ & RSD \\
\hline 1 & $0.994 \pm 0.015$ & 1.52 & $0.985 \pm 0.018$ & 1.81 \\
\hline 5 & $5.030 \pm 0.074$ & 1.48 & $5.041 \pm 0.092$ & 1.83 \\
\hline 20 & $19.920 \pm 0.243$ & 1.22 & $19.840 \pm 0.280$ & 1.41 \\
\hline 30 & $29.886 \pm 0.292$ & 0.98 & $29.861 \pm 0.233$ & 0.78 \\
\hline 45 & $44.759 \pm 0.255$ & 0.57 & $44.742 \pm 0.326$ & 0.73 \\
\hline
\end{tabular}

TABLE 4: System suitability.

\begin{tabular}{lcc}
\hline Parameters & Mean & RSD \\
\hline Theoretical plates (Drug) & 7716 & 1.25 \\
Plates/meter & 30864 & 1.25 \\
HETP & 31.10 & 0.13 \\
Tailing factor & 1.10 & 0.11 \\
LOD $(\mu \mathrm{g} / \mathrm{mL})$ & 0.1498 & 1.05 \\
LOQ $(\mu \mathrm{g} / \mathrm{mL})$ & 0.4541 & 1.05 \\
Resolution $(\mathrm{Rs})$ & 11.0 & 0.45 \\
Retention time of drug & $3.95 \mathrm{~min}$ & 1.50 \\
Retention time of IS & $7.80 \mathrm{~min}$ & 1.50 \\
\hline
\end{tabular}

was used to study robustness of the method. A $2^{4}$ factorial design was used to test the robustness of chromatographic separation. The experimental design is useful for this kind of study as it facilitates the investigation of several parameters by reducing the number of experiments. Acetonitrile content of the mobile phase, $\mathrm{pH}$, column oven temperature, and flow rate was investigated. Upper and lower limits are shown in Table 5. The experiments were run randomly with sample containing gemcitabine and internal standard $(20 \mu \mathrm{g} / \mathrm{mL}$ of each). The selected responses were resolution $\left(R_{s}\right)$, tailing factor of drug $\left(T_{f}-\mathrm{D}\right)$, and tailing factor of IS $\left(T_{f}-\mathrm{I}\right)$.

2.5.5. Stability Studies. Stress study like oxidative, alkaline, and acidic stress, exposure to sunlight and UV light (254 nm), was carried out using raw material. Chromatograms were recorded in order to study the specificity of the method. The chromatograms of the samples were compared with those of control samples that were freshly prepared from the stock standard solution and without stress. All samples were analyzed in triplicate. The peak purity was checked using the tools of the LC-Solution software. This assessment was based on the comparison of spectra recorded during the elution of the peak. UV spectra and peak purity were used to assess purity of analytes.

(1) Oxidative Stress. Gemcitabine (5 mg) was weighed accurately and transferred to $100 \mathrm{~mL}$ flask for evaluation of oxidative stress. $10 \mathrm{~mL}$ of $5 \%$ hydrogen peroxide was added to it. It was shaken for one hour at $60^{\circ} \mathrm{C}$ and then contents were cooled to room temperature. Internal standard $(2 \mathrm{~mL})$ was

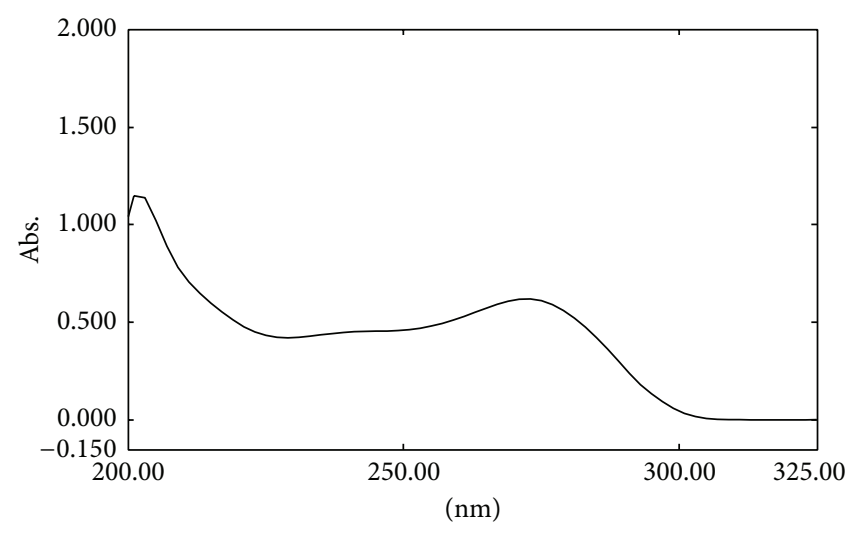

FIGURE 2: UV spectra of the gemcitabine in mobile phase.

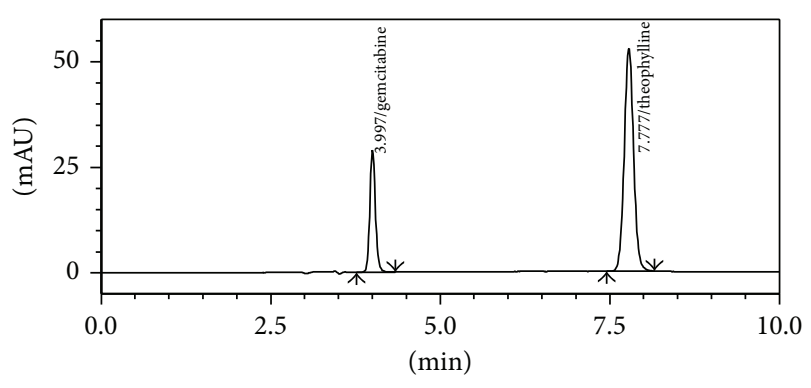

1 PDA multi $1 / 275 \mathrm{~nm} 4 \mathrm{~nm}$

FIgURE 3: Representative chromatogram showing signals of gemcitabine and theophylline in the selected mobile phase.

added; the contents were transferred quantitatively to $100 \mathrm{~mL}$ volumetric flask and diluted to the mark with mobile phase.

(2) Effect of Acidic, Alkaline, and Aqueous Media. Similarly for evaluation of acidic, alkaline, or hydrolytic stress, gemcitabine $(5 \mathrm{mg}$ ) was weighed accurately and transferred to $100 \mathrm{~mL}$ flask. These samples were shaken (at $60^{\circ} \mathrm{C}, 1 \mathrm{~h}$ ) with either hydrochloric acid $(5 \mathrm{~mL}, 1 \mathrm{~N} \mathrm{HCl})$ or sodium hydroxide ( $5 \mathrm{~mL}, 1 \mathrm{~N} \mathrm{NaOH}$ or $20 \mathrm{~mL}$ water). After one hour the content was cooled and processed as described above (in oxidative stress).

(3) Effect of UV Light or Sunlight. Gemcitabine (500 mg) was placed in an open watch glass and exposed to either 
TABLE 5: Factorial design data for robustness of chromatographic separation.

(a)

\begin{tabular}{lcc}
\hline Selected parameters and their variations & -1 (lower limit) & +1 (upper limit) \\
\hline Acetonitrile in mobile phase $(\%)(A)$ & 8 & 12 \\
Final pH of the mobile phase $(B)$ & 6.8 & 7.2 \\
Column oven temperature $\left({ }^{\circ} \mathrm{C}\right)(C)$ & 20 & 30 \\
Flow rate $(\mathrm{mL} / \mathrm{min})(D)$ & 0.8 & 1.2 \\
\hline
\end{tabular}

(b)

\begin{tabular}{|c|c|c|c|c|c|c|c|c|}
\hline Exp. number & Run order & $A$ & $B$ & $C$ & $D$ & $R_{s}$ & $T_{f}-\mathrm{D}$ & $T_{f}-\mathrm{I}$ \\
\hline 1 & 6 & 8 & 6.8 & 20 & 0.8 & 14.01 & 1.12 & 1.2 \\
\hline 2 & 11 & 12 & 6.8 & 20 & 0.8 & 13.1 & 1.11 & 1.19 \\
\hline 3 & 5 & 8 & 7.2 & 20 & 0.8 & 14.1 & 1.09 & 1.18 \\
\hline 4 & 13 & 12 & 7.2 & 20 & 0.8 & 13.2 & 1.08 & 1.1 \\
\hline 5 & 1 & 8 & 6.8 & 30 & 0.8 & 14.3 & 1.09 & 1.11 \\
\hline 6 & 7 & 12 & 6.8 & 30 & 0.8 & 10.2 & 1.09 & 1.08 \\
\hline 7 & 10 & 8 & 7.2 & 30 & 0.8 & 14.5 & 1.11 & 1.15 \\
\hline 8 & 15 & 12 & 7.2 & 30 & 0.8 & 11.85 & 1.1 & 1.08 \\
\hline 9 & 12 & 8 & 6.8 & 20 & 1.2 & 13.51 & 1.13 & 1.11 \\
\hline 10 & 14 & 12 & 6.8 & 20 & 1.2 & 10.21 & 1.05 & 1.07 \\
\hline 11 & 9 & 8 & 7.2 & 20 & 1.2 & 14.41 & 1.09 & 1.12 \\
\hline 12 & 2 & 12 & 7.2 & 20 & 1.2 & 10.05 & 1.06 & 1.07 \\
\hline 13 & 8 & 8 & 6.8 & 30 & 1.2 & 13.25 & 1.12 & 1.1 \\
\hline 14 & 4 & 12 & 6.8 & 30 & 1.2 & 10.15 & 1.04 & 1.07 \\
\hline 15 & 3 & 8 & 7.2 & 30 & 1.2 & 14.12 & 1.1 & 1.11 \\
\hline 16 & 16 & 12 & 7.2 & 30 & 1.2 & 10.15 & 1.05 & 1.05 \\
\hline
\end{tabular}

$R_{s}$ : resolution factor, $T_{f}$-D: tailing factor for drug, and $T_{f}$-I: tailing factor for IS.

UV-irradiation $\left(\sim 100 \mathrm{~W} / \mathrm{m}^{2}\right)$ or direct sunlight for one hour with occasionally shifting of the content using stainless steel spatula. After exposure, $5 \mathrm{mg}$ of sample was weighed and transferred to $100 \mathrm{~mL}$ volumetric flask; internal standard $(2 \mathrm{~mL})$ was added to it and further processed as described above.

Chromatograms of these sample solutions were recorded and compared with the chromatograms of unexposed API.

(4) Stock Stability. The stability of stock solution was evaluated at zero time and stored in the refrigerator $\left(2-8^{\circ} \mathrm{C}\right)$. Samples were prepared and analyzed at days $0,7,14$, and 21 .

\section{Results and Discussion}

3.1. Analytical Method Development. In order to achieve optimum separation various parameters like solvent, solvent strength, detection wavelength, flow rate, elution time, asymmetry, and plate numbers were considered. During optimization gemcitabine hydrochloride and internal standard were injected into various mobile phases of water: methanol or water : acetonitrile $(90: 10,80: 20,70: 30,60: 40$, and $50: 50$, pH 5, 6, or 7) and the retention time, tailing factor along with resolution factor, was recorded. In certain mobile phases the peak was distorted while in others the compound eluted out quickly indicating the lesser retention time and thus lesser separation on the column. As the $\mathrm{pKa}$ of gemcitabine is 3.5 and unstable in an acidic pH [3], different mobile phases of $\mathrm{pH} 7.0$ were used. Mobile phase of acetonitrile-water $(10: 90$, $\mathrm{v} / \mathrm{v}, \mathrm{pH}$ adjusted to 7.0) was used as suitable mobile phase, as it was able to separate the analytes. Using the C-18 ODS analytical column with an isocratic mobile phase at a flow rate of $1 \mathrm{~mL} / \mathrm{min}$, the drug and IS were eluted at $\sim 4.0$ and $7.8 \mathrm{~min}$, respectively. Although temperature was found not to be a critical parameter for this analysis, it was set at $25^{\circ} \mathrm{C}$ to avoid shifting of signals. The absorption maximum of the drug at $275 \mathrm{~nm}$ was selected for detection (Figure 2), as there was no interference from excipients present in drug or baseline disturbance. The resolution factor was $\sim 11$. Figure 3 depicts the representative chromatogram obtained with the present method.

3.2. Method Validation. The method was validated with respect to parameters including linearity, limit of quantitation (LOQ), limit of detection (LOD), precision, accuracy, specificity, robustness, system suitability, and stability.

3.2.1. Linearity. Different calibration curves $(n=6)$ that were constructed for gemcitabine were linear over the concentration range of $0.5-50 \mu \mathrm{g} / \mathrm{mL}$. Peak area ratios of gemcitabine to IS were plotted versus gemcitabine concentration and 


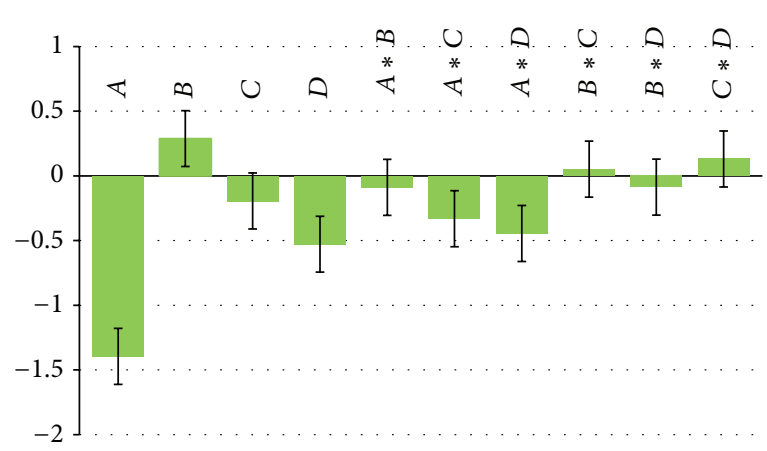

(a)

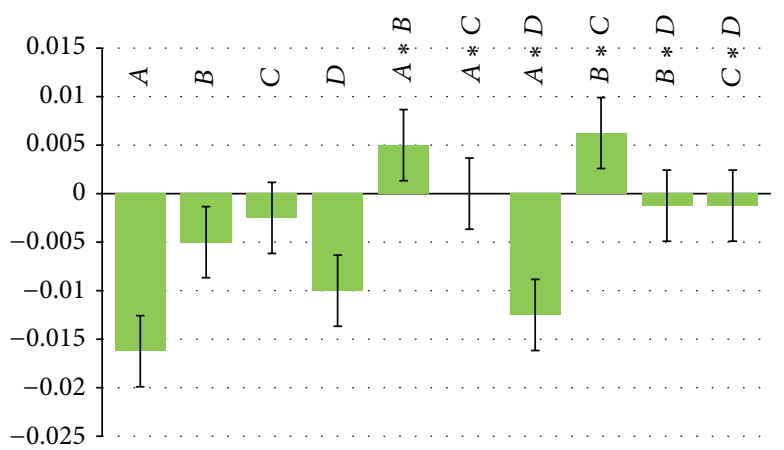

(b)

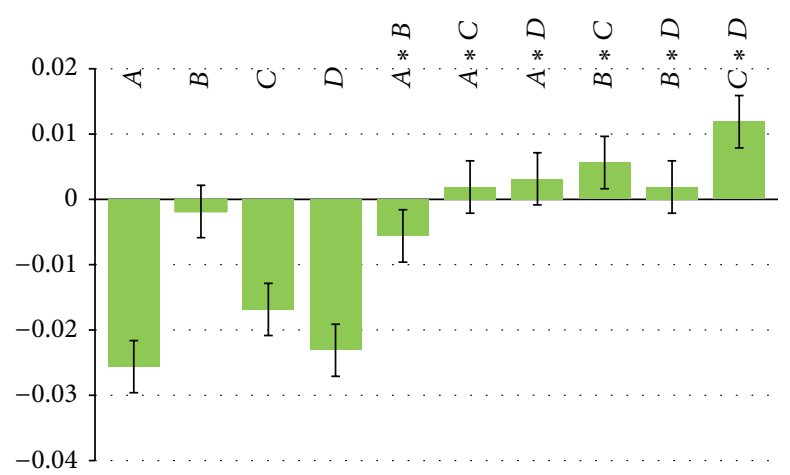

(c)

FIGURE 4: Scaled and centered coefficient of variation (\%) of (a) resolution factor, (b) tailing factor of drug, and (c) tailing factor of I.S. during robustness studies.

TABLE 6: Stability data under different stressed conditions.

\begin{tabular}{|c|c|c|}
\hline Stress conditions & Percent gemcitabine remained & Retention time of degraded products \\
\hline Alkaline stress $\left(1 \mathrm{~N}, \mathrm{NaOH}, 60^{\circ} \mathrm{C}, 1 \mathrm{~h}\right)$ & $16.1 \pm 0.2 \%$ & $\begin{array}{c}3.023(\mathrm{~d}-1), 3.202(\mathrm{~d}-2), 3.645(\mathrm{~d}-3), 4.342(\mathrm{~d}-4), 4.944 \\
(\mathrm{~d}-5) \text {, and } 5.375(\mathrm{~d}-6)\end{array}$ \\
\hline Acidic stress $\left(1 \mathrm{~N} \mathrm{HCl}, 60^{\circ} \mathrm{C}, 1 \mathrm{~h}\right)$ & $95.0 \pm 0.2 \%$ & $4.953(\mathrm{~d}-5), 6.082(\mathrm{~d}-7)$, and $7.131(\mathrm{~d}-8)$ \\
\hline Oxidative stress $\left(5 \%, 60^{\circ} \mathrm{C}, 1 \mathrm{~h}\right)$ & $97.1 \pm 0.1 \%$ & $3.772(d-3)$ \\
\hline Aqueous hydrolytic stress $\left(60^{\circ} \mathrm{C}, 1 \mathrm{~h}\right)$ & $99.2 \pm 0.1 \%$ & $4.952(d-5)$ \\
\hline Ultraviolet light $\left(100 \mathrm{~W} / \mathrm{m}^{2}, 1 \mathrm{~h}\right)$ & $100.0 \%$ & 0.0 \\
\hline Direct sunlight $(1 \mathrm{~h})$ & $100.0 \%$ & 0.0 \\
\hline Aqueous stability (after 21 days) & $99.9 \pm 0.1 \%$ & 0.0 \\
\hline
\end{tabular}

TABLE 7: Assay of formulations.

\begin{tabular}{|c|c|c|c|c|}
\hline Sample & Label claim (mg/vial) $(n=6)$ & $\begin{array}{c}\text { Amount found } \\
\text { Mean } \pm \text { SD }\end{array}$ & $\%$ assay & $\%$ RSD \\
\hline Batch 1 & 200 & $199.35 \pm 0.46$ & 99.7 & 0.23 \\
\hline Batch 2 & 200 & $199.27 \pm 0.52$ & 99.6 & 0.26 \\
\hline
\end{tabular}

linear regression was performed using Spinchrome-Clarity or LC-solution software. Different calibration curves $(n=6)$ were prepared on three different days. The mean regression equation for gemcitabine was found to be $y=0.0353 x+$ 0.0063 with 0.9998 correlation coefficient, using weighting factor- $x$ (Table 1). The linearity range reported in other methods ranged between 0.020 and $300 \mu \mathrm{g} / \mathrm{mL}$ [3, 5-28].

3.2.2. $L O D$ and LOQ. The LOD and LOQ values were 0.1498 and $0.4541 \mu \mathrm{g} / \mathrm{mL}$ calculated using calibration curve as per 


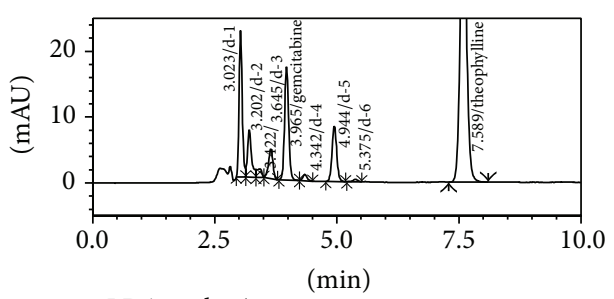

1 PDA multi1/275nm $4 \mathrm{~nm}$

(a)

ID\#: 2

Retention time: 3.964

Compound name: gemcitabine

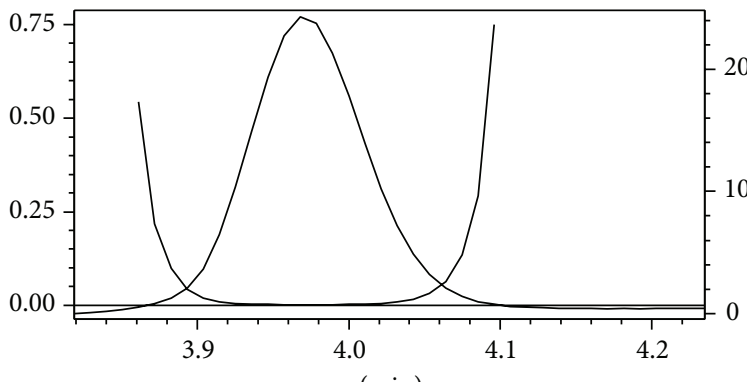

Impurity: not detected

Peak purity index: 1.000000

Single point threshold: 0.998065

Minimum peak purity index: 1934

(c)

ID\#: 6

Retention time: 3.023

Compound name: $\mathrm{d}-1$

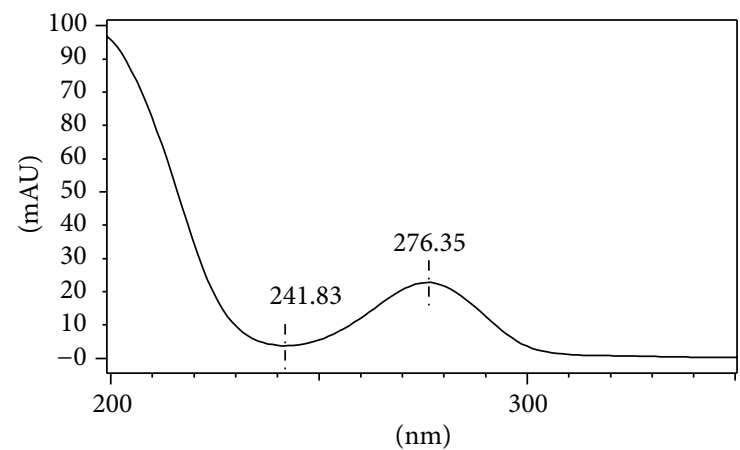

(e)

ID\#:9

Retention time: 4.342

Compound name: $\mathrm{d}-4$

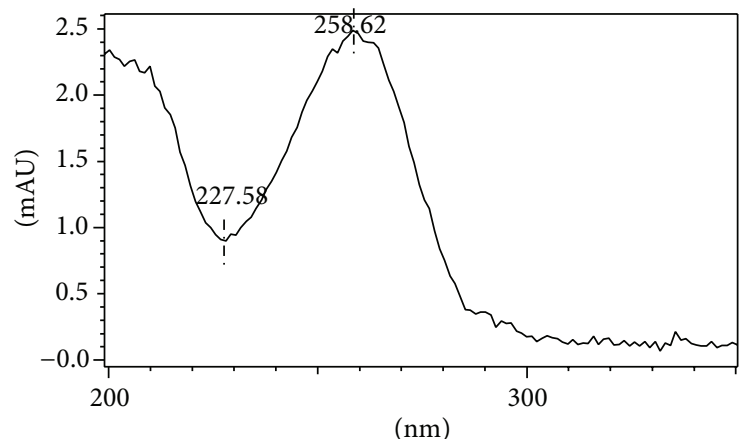

(g)

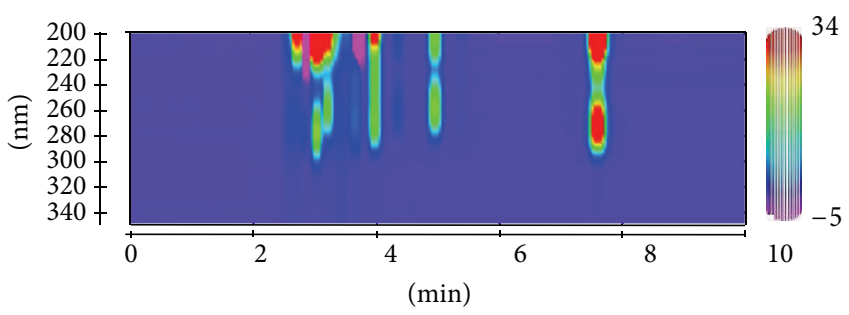

(b)

ID\#:2

Retention time: 3.965

Compound name: gemcitabine

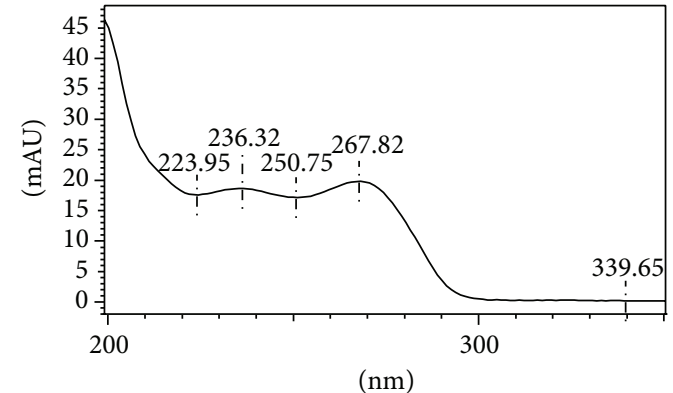

(d)

ID\#: 7

Retention time: 3.202

Compound name: $\mathrm{d}-2$

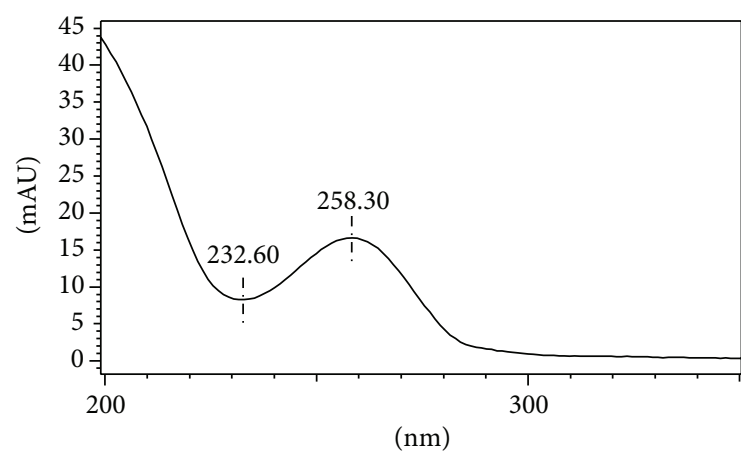

(f)

ID\#: 3

Retention time: 4.944

Compound name: $\mathrm{d}-5$

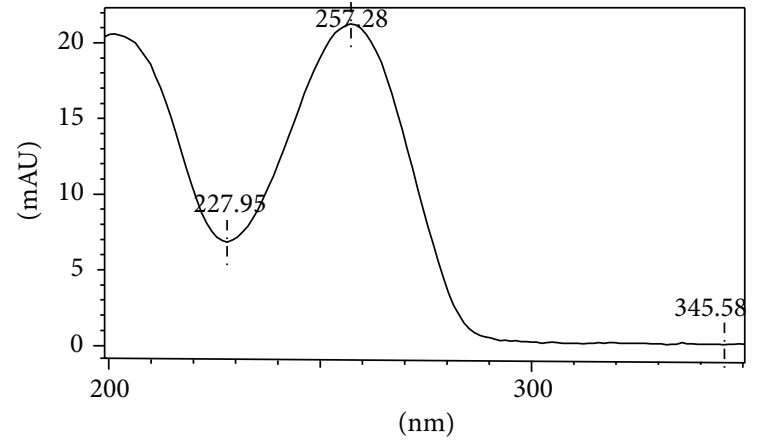

(h)

FIgURE 5: Continued. 


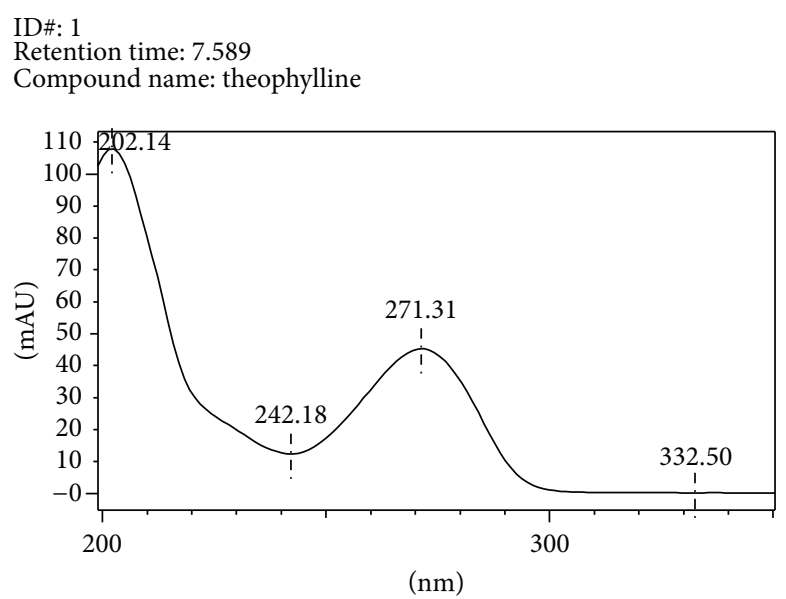

(i)

Figure 5: Typical HPLC chromatogram of (a) gemcitabine exposed to alkaline stress $\left(1 \mathrm{~N} \mathrm{NaOH}, 60^{\circ} \mathrm{C}, 1 \mathrm{~h}\right.$ ), (b) contour plot, (c) peak purity index, and extracted UV spectra of (d) gemcitabine, (e) degraded product d-1, (f) d-2, (g) d-4, (h) d-5, and (i) theophylline.

ICH guideline. The LOD and LOQ reported by Lanz et al. [14] were 10 and $20 \mathrm{ng} / \mathrm{mL}$, based on signal to noise ratio method, while Xu et al. [7] reported 12 and $37.5 \mathrm{ng} / \mathrm{mL}$ based on calibration curve (external standard method).

3.2.3. Accuracy and Precision. The accuracy and precision of the analytical method were established across its linear range as indicated in the guideline. As shown from the data in Table 2, excellent recoveries were made at different added concentration level. The results obtained for the intraday and interday precision of the method, expressed as RSD values. As shown in the table, the intraday and interday RSD were $<2.0 \%$ for all concentrations tested in different situations studied (Tables 2 and 3 ).

3.2.4. Specificity. Specificity of the method was assessed by comparing the chromatograms obtained from lyophilized powder, from internal standard, and from the drug standards. The retention times of drug from standard solutions and from lyophilized powder were identical and no coeluting peaks from the diluents were observed, indicating specific method for quantitative estimation of drug in the commercial formulation.

3.2.5. System Suitability. System suitability parameters were studied with six replicates standard solution of the drug and the calculated parameters are within the acceptance criteria. The tailing factor, the number of theoretical plates, and HETP were in the acceptable limits (RSD less than 2\%). The system suitability results are shown in Table 4.

3.2.6. Robustness. Robustness of the methods was illustrated by getting the resolution factor and tailing factor, when mobile phase flow rate $( \pm 0.2 \mathrm{~mL} / \mathrm{min})$, acetonitrile content $( \pm 2 \%), \mathrm{pH}\left( \pm 0.2\right.$ units), and column temperature $\left( \pm 5^{\circ} \mathrm{C}\right)$ were deliberately varied. It was studied using factorial design experiment. The deliberate changes in the method do not affected the resolution, tailing factor of drug, and IS significantly. The scaled and centered coefficient plots for the above responses revealed that different parameters did not affect responses, so that the developed method was considered rugged and robust. Results are presented in Figure 4 and Table 5.

3.2.7. Stability Studies. The prepared stock and working solutions were stable up to 21 days when stored in refrigerator $\left(2-8^{\circ} \mathrm{C}\right)$ and did not produce degraded compounds during experimental conditions. The peak purity was 0.985 or more during the validation studies. Gemcitabine produces six different degradation products on alkaline stress with retention time ( $\mathrm{min}) 3.023$ (as d-1), 3.202 (d-2), 3.645 (d3), 4.342 (d-4), 4.944 (d-5), and 5.375 (d-6). The percentage of gemcitabine remained was $16.1 \%$. Mastanamma et al. [11] and Kudikala et al. [12] have reported two degraded product of gemcitabine. Figure 5 represents the chromatogram, contour plot, peak purity, and UV spectra of gemcitabine and degraded products. The extracted UV spectra indicate that the entire degradation products are derived from gemcitabine or its intermediates. In case of acidic stress the degradation products were observed at 4.953 (as d-5), 6.082 (d-7), and $7.131 \mathrm{~min}$ (d-8) (Figure 6). Jansen et al. [3] have reported the presence of a coeluted degraded product with gemcitabine which does not possess UV absorption at $275 \mathrm{~nm}$. The hydrolytic product d-5 (4.95 min) was observed in alkaline as well as in aqueous stress condition. On exposure to hydrogen peroxide $\left(5 \%, 60^{\circ} \mathrm{C}, 1 \mathrm{~h}\right)$, gemcitabine produces only one minor degradation products having retention time $3.772 \mathrm{~min}$ (Table 6, Figure 7). The percentage of unoxidized gemcitabine was $97.1 \%$. Gemcitabine was completely degraded on exposure to drastic oxidative condition $(50 \%$, $60^{\circ} \mathrm{C}, 1 \mathrm{~h}$ ). However, these degraded compounds have no ultraviolet (UV) absorbance at $275 \mathrm{~nm}$, the wavelength used to monitor the gemcitabine concentrations. Borisagar et al. 


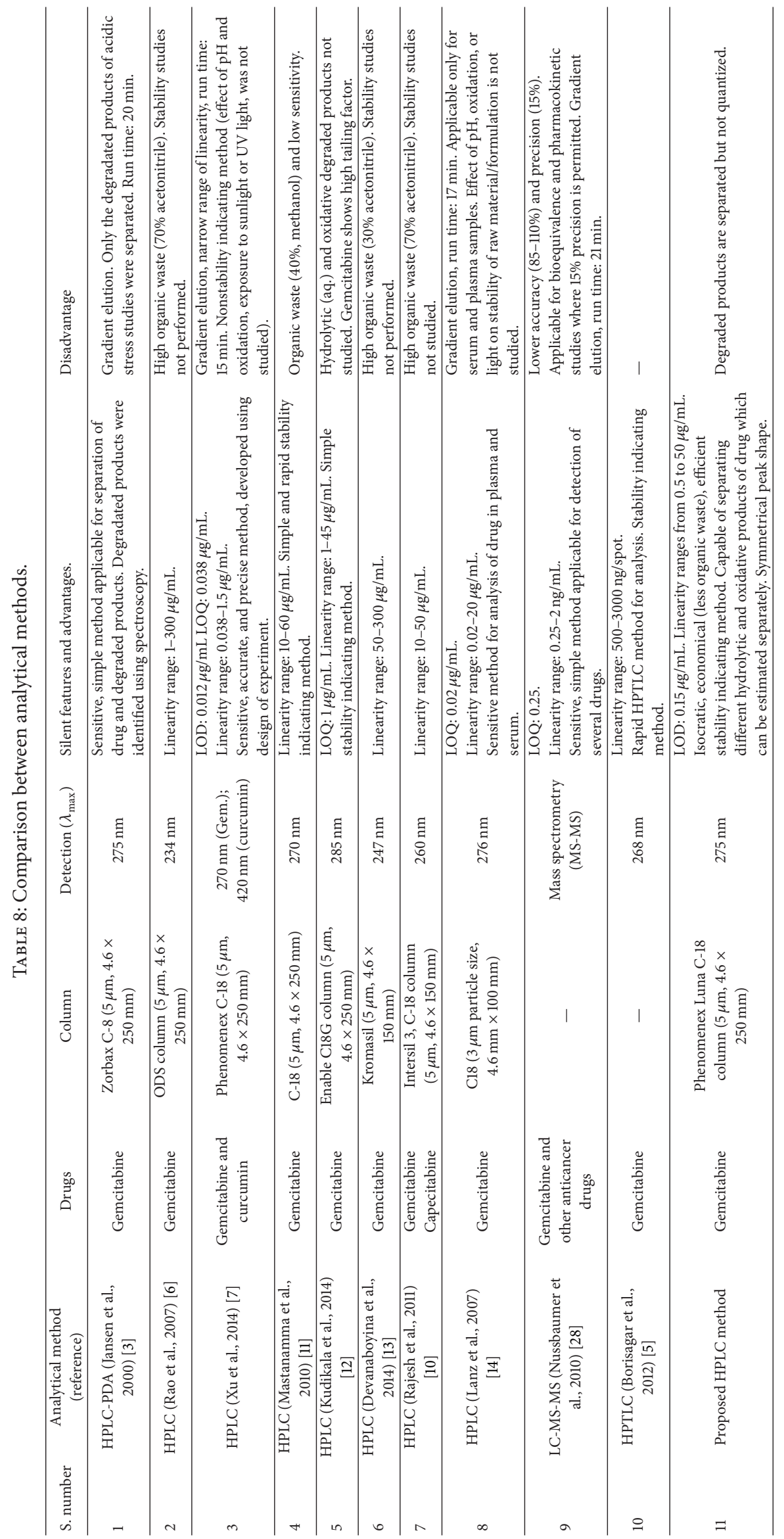




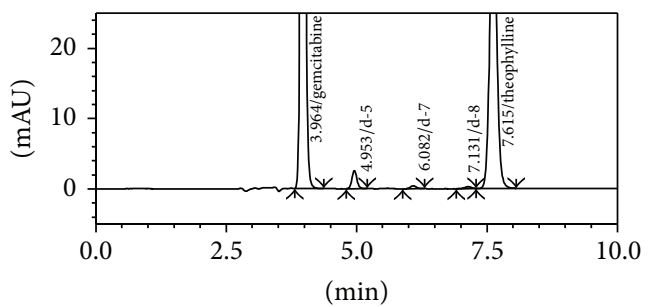

1 PDA multi $1 / 275 \mathrm{~nm} 4 \mathrm{~nm}$

(a)

ID\#: 2

Retention time: 3.964

Compound name: gemcitabine

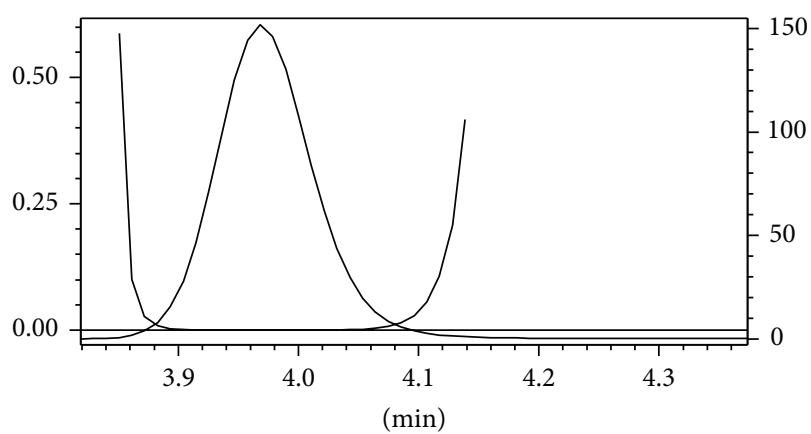

Impurity: not detected

Peak purity index: 1.000000

Single point threshold: 0.999923

Minimum peak purity index: 76

(c)

ID\#: 10

Retention time: 6.082

Compound name: $\mathrm{d}-7$

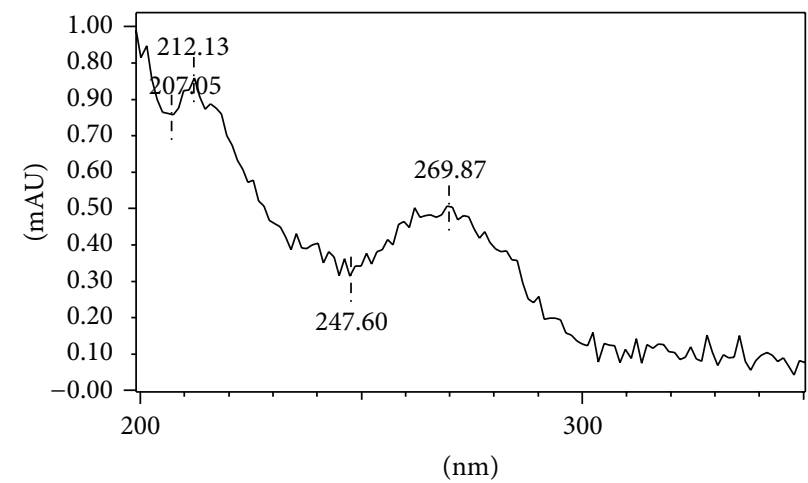

(e)

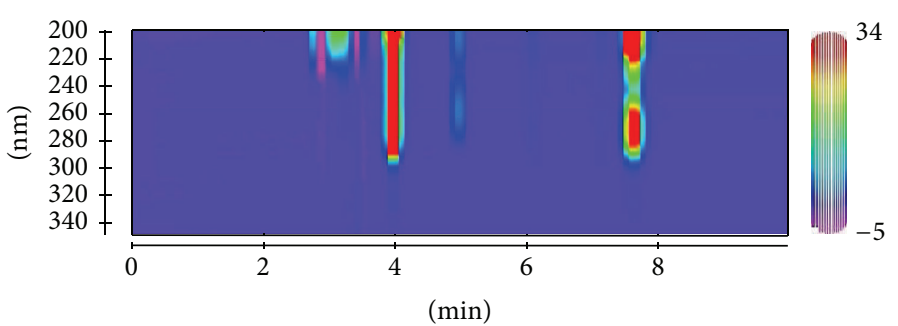

(b)

ID\#: 3

Retention time: 4.953

Compound name: $\mathrm{d}-5$

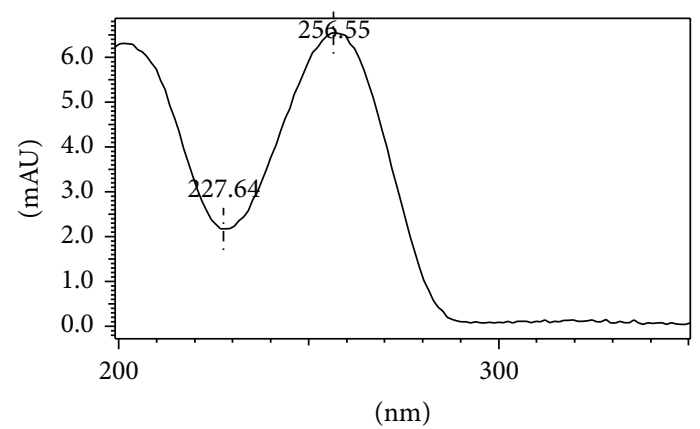

(d)

\section{ID\#: 5}

Retention time: 7.131

Compound name: $\mathrm{d}-8$

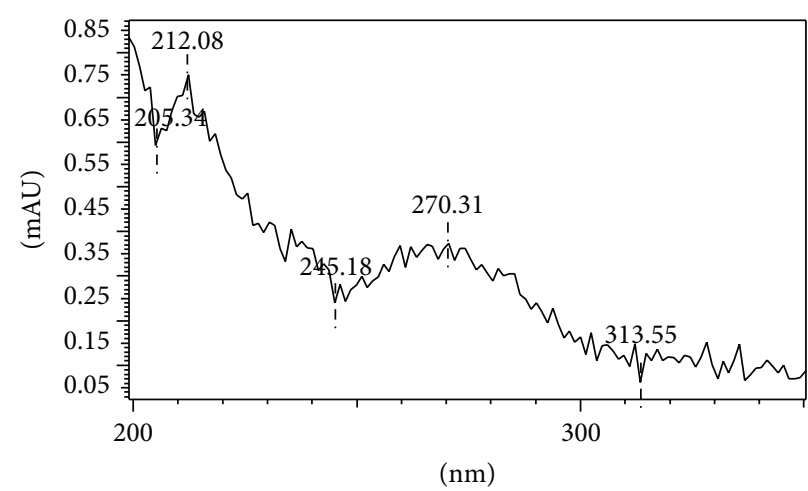

(f)

Figure 6: Typical HPLC chromatogram of (a) gemcitabine exposed to acidic stress $\left(1 \mathrm{~N} \mathrm{HCl}, 60^{\circ} \mathrm{C}, 1 \mathrm{~h}\right)$, (b) contour plot, (c) peak purity index, and extracted UV spectrum of (d) degraded product d-5, (e) d-7, and (f) d-8.

[5] reported the oxidative degradation [13.8\%] of gemcitabine utilizing HPTLC. The present results indicate that, using appropriate chromatographic conditions, the structurally related degraded products of gemcitabine can be separated which were not studied earlier (Table 8).
3.2.8. Assay. The proposed method was applied to the determination gemcitabine in injectable formulations. The results of these assay yielded $99.6 \%$ (RSD, $0.26 \%$ ) of labeled claimed. Low value of precision indicates that the method can be used precisely for the estimation of drug in formulations (Table 7). 


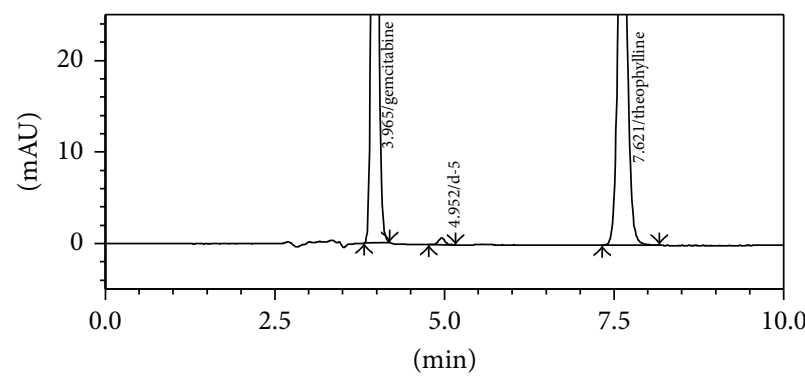

1 PDA multi $1 / 275 \mathrm{~nm} 4 \mathrm{~nm}$

(a)

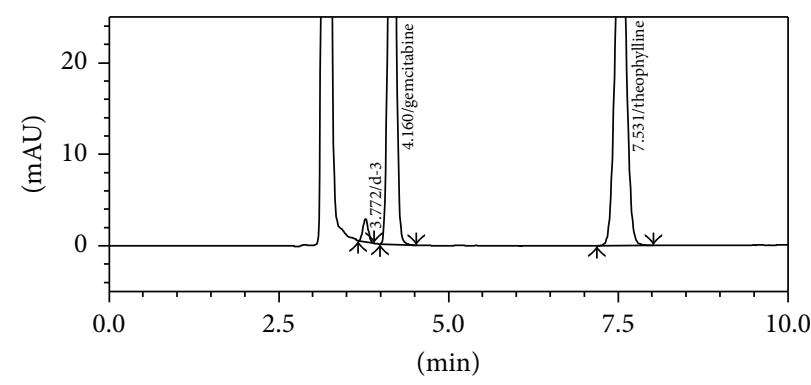

1 PDA multi $1 / 275 \mathrm{~nm} 4 \mathrm{~nm}$

(b)

FIgURE 7: Typical HPLC chromatogram of gemcitabine exposed to (a) hydrolytic $\left(\mathrm{H}_{2} \mathrm{O}, 60^{\circ} \mathrm{C}, 1 \mathrm{~h}\right)$ and $(\mathrm{b})$ oxidative stress $\left(5 \%, 60^{\circ} \mathrm{C}, 1 \mathrm{~h}\right)$.

\section{Conclusion}

A validated HPLC method has been developed for determination of gemcitabine in formulations. The proposed stability indicating method is simple, economical, accurate, precise, specific, and robust. Method is capable of separating different degraded products of drug which can be estimated separately. The experimental design was found to be very useful in testing the robustness of chromatographic separation during the validation step. Hence this method can be easily and conveniently adopted for the routine analysis of gemcitabine in pharmaceutical dosage form.

\section{Conflict of Interests}

The authors declare that there is no conflict of interests regarding the publication of this paper.

\section{Acknowledgments}

The authors wish to thank the Head of Faculty of Pharmacy, Integral University, Lucknow, India, and the Dean of Faculty of Pharmacy and Medical Sciences, Al-Ahliyya Amman University, Amman, Jordan, for providing necessary facilities.

\section{References}

[1] Q. Xu, Y. Zhang, and L. A. Trissel, "Physical and chemical stability of gemcitabine hydrochloride solutions," Journal of the American Pharmaceutical Association (Washington), vol. 39, no. 4, pp. 509-513, 1999.

[2] S. L. Anliker, M. S. McClure, T. C. Britton, E. A. Stephan, S. R. Maple, and G. G. Cooke, "Degradation chemistry of gemcitabine hydrochloride, a new antitumor agent," Journal of Pharmaceutical Sciences, vol. 83, no. 5, pp. 716-719, 1994.

[3] P. J. Jansen, M. J. Akers, R. M. Amos et al., "The degradation of the antitumor agent gemcitabine hydrochloride in an acidic aqueous solution at pH 3.2 and identification of degradation products," Journal of Pharmaceutical Sciences, vol. 89, no. 7, pp. 885-891, 2000.

[4] D. G. Sankar, P. V. M. Latha, B. A. Kumar, and P. J. Babu, "UV spectrophotometric determination of temozolamide and gemcitabine," Asian Journal of Chemistry, vol. 19, no. 2, pp. 16051607, 2007.

[5] S. L. Borisagar, H. U. Patel, and C. Patel, "A validated stabilityindicating HPTLC method for the estimation of gemcitabine $\mathrm{HCl}$ in its dosage form," Journal of Planar Chromatography, vol. 25, no. 1, pp. 77-80, 2012.

[6] J. V. L. N. S. Rao, M. M. Krishna, P. B. Prakash, and P. R. Kumar, "RP-HPLC analysis of gemcitabine in pure form and in pharmaceutical dosage forms," Asian Journal of Chemistry, vol. 19, no. 5, pp. 3399-3402, 2007.

[7] H. Xu, J. Paxton, J. Lim, Y. Li, and Z. Wu, "Development of a gradient high performance liquid chromatography assay for simultaneous analysis of hydrophilic gemcitabine and lipophilic curcumin using a central composite design and its application in liposome development," Journal of Pharmaceutical and Biomedical Analysis, vol. 98, pp. 371-378, 2014.

[8] S. S. Bansal, C. Celia, S. Ferrati et al., "Validated RP-HPLC method for the simultaneous analysis of gemcitabine and LY364947 in liposomal formulations," Current Drug Targets, vol. 14, no. 9, pp. 1061-1069, 2013.

[9] Q. Zhou, L. Liu, D. Zhang, and X. Fan, "Analysis of gemcitabine liposome injection by HPLC with evaporative light scattering detection," Journal of Liposome Research, vol. 22, no. 4, pp. 263269, 2012.

[10] V. Rajesh, B. Anupama, V. Jagathi, and P. Sai Praveen, "Simultaneous estimation of gemcitabine hydrochloride and capecitabine hydrochloride in combined tablet dosage form by RP-HPLC method," E-Journal of Chemistry, vol. 8, no. 3, pp. 1212-1217, 2011.

[11] S. Mastanamma, G. Ramkumar, D. A. Kumar, and J. V. L. N. S. Rao, "A stability indicating RP-HPLC method for the estimation of gemcitabine $\mathrm{HCl}$ in injectable dosage forms," E-Journal of Chemistry, vol. 7, no. S1, pp. S239-S244, 2010.

[12] S. Kudikala, S. R. Malladi, S. Thota, and V. R. Kumar, "RP-HPLC method for the estimation gemcitabine in API and parenteral dosage form," Journal of Scientific Research in Pharmacy, vol. 3, pp. 16-18, 2014.

[13] N. Devanaboyina, S. Sushma, B. Sekhar, E. Asha, K. Mutyalamma, and N. Trimurthulu, "A novel RP-HPLC method development and validation for analysis of gemcitabine in bulk and pharmaceutical dosage form," International Journal of Pharma Sciences, vol. 4, pp. 522-525, 2014.

[14] C. Lanz, M. Früh, W. Thormann, T. Cerny, and B. H. Lauterburg, "Rapid determination of gemcitabine in plasma and serum 
using reversed-phase HPLC," Journal of Separation Science, vol. 30, no. 12, pp. 1811-1820, 2007.

[15] M. N. Kirstein, I. Hassan, D. E. Guire et al., "High-performance liquid chromatographic method for the determination of gemcitabine and $2^{\prime}, 2^{\prime}$-difluorodeoxyuridine in plasma and tissue culture media," Journal of Chromatography B, vol. 835, no. 1-2, pp. 136-142, 2006.

[16] R. Losa, M. I. Sierra, M. O. Gión, E. Esteban, and J. M. Buesa, "Simultaneous determination of gemcitabine di- and triphosphate in human blood mononuclear and cancer cells by RP-HPLC and UV detection," Journal of Chromatography B: Analytical Technologies in the Biomedical and Life Sciences, vol. 840, no. 1, pp. 44-49, 2006.

[17] R. Losa, M. I. Sierra, C. Guardado et al., "Development and validation of an ion pair HPLC method for gemcitabine and $2^{\prime}, 2$-difluoro-2'-deoxyuridine determination," Analytica Chimica Acta, vol. 528, no. 2, pp. 255-260, 2005.

[18] B. Yilmaz and Y. Kadioglu, "Comparison of zero- and secondorder derivative spectrophotometric and HPLC methods for the determination of gemcitabine in human plasma," Il-Farmaco, vol. 59, no. 5, pp. 425-429, 2004.

[19] B. Keith, Y. Xu, and J. L. Grem, "Measurement of the anti-cancer agent gemcitabine in human plasma by high-performance liquid chromatography," Journal of Chromatography B, vol. 785, no. 1, pp. 65-72, 2003.

[20] B. Yilmaz, Y. Kadığlu, and Y. Aksoy, "Simultaneous determination of gemcitabine and its metabolite in human plasma by high-performance liquid chromatography," Journal of Chromatography B: Analytical Technologies in the Biomedical and Life Sciences, vol. 791, no. 1-2, pp. 103-109, 2003.

[21] K. B. Freeman, S. Anliker, M. Hamilton et al., "Validated assays for the determination of gemcitabine in human plasma and urine using high-performance liquid chromatography with ultraviolet detection," Journal of Chromatography B: Biomedical Applications, vol. 665, no. 1, pp. 171-181, 1995.

[22] N.-M. Lin, S. Zeng, S.-L. Ma, Y. Fan, H.-J. Zhong, and L. Fang, "Determination of gemcitabine and its metabolite in human plasma using high-pressure liquid chromatography coupled with a diode array detector," Acta Pharmacologica Sinica, vol. 25, no. 12, pp. 1584-1589, 2004.

[23] Y. Xu, B. Keith, and J. L. Grem, "Measurement of the anticancer agent gemcitabine and its deaminated metabolite at low concentrations in human plasma by liquid chromatography-mass spectrometry," Journal of Chromatography B, vol. 802, no. 2, pp. 263-270, 2004.

[24] E. Marangon, F. Sala, O. Caffo, E. Galligioni, M. D’Incalci, and M. Zucchetti, "Simultaneous determination of gemcitabine and its main metabolite, dFdU, in plasma of patients with advanced non-small-cell lung cancer by high-performance liquid chromatography-tandem mass spectrometry," Journal of Mass Spectrometry, vol. 43, no. 2, pp. 216-223, 2008.

[25] H. Khoury, A. Deroussent, L. H. Reddy, P. Couvreur, G. Vassal, and A. Paci, "Simultaneous determination of gemcitabine and gemcitabine-squalene by liquid chromatography-tandem mass spectrometry in human plasma," Journal of Chromatography B: Analytical Technologies in the Biomedical and Life Sciences, vol. 858, no. 1-2, pp. 71-78, 2007.

[26] L. D. Vainchtein, H. Rosing, B. Thijssen, J. H. M. Schellens, and J. H. Beijnen, "Validated assay for the simultaneous determination of the anti-cancer agent gemcitabine and its metabolite 2/,2I-difluorodeoxyuridine in human plasma by high-performance liquid chromatography with tandem mass spectrometry," Rapid Communications in Mass Spectrometry, vol. 21, no. 14, pp. 2312-2322, 2007.

[27] R. Honeywell, A. C. Laan, C. J. van Groeningen et al., "The determination of gemcitabine and 2 -deoxycytidine in human plasma and tissue by APCI tandem mass spectrometry," Journal of Chromatography B, vol. 847, no. 2, pp. 142-152, 2007.

[28] S. Nussbaumer, S. Fleury-Souverain, P. Antinori et al., "Simultaneous quantification of ten cytotoxic drugs by a validated LCESI-MS/MS method," Analytical and Bioanalytical Chemistry, vol. 398, no. 7-8, pp. 3033-3042, 2010.

[29] IFPMA, "ICH validation of analytical procedures: text and methodology Q2 (R1)," in Proceedings of the International Conference on Harmonization, pp. 1-13, IFPMA, Geneva, Switzerland, 2005. 

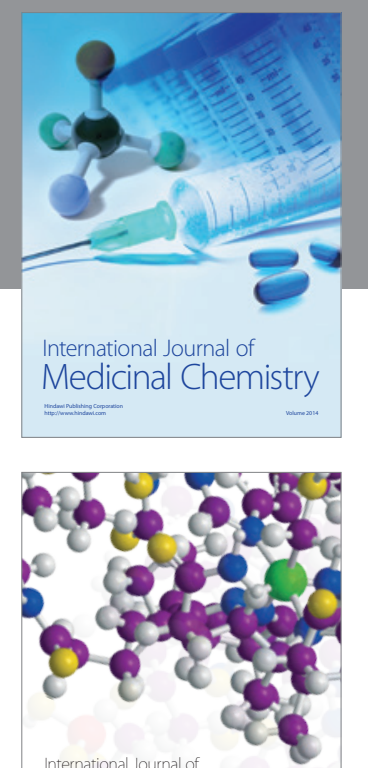

\section{Carbohydrate} Chemistry

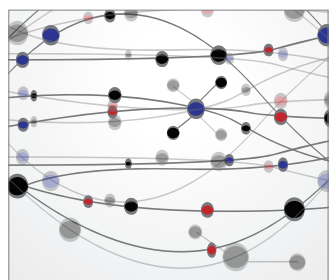

The Scientific World Journal
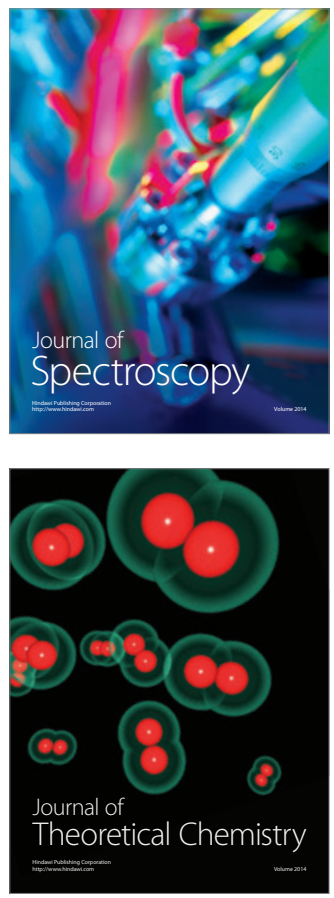
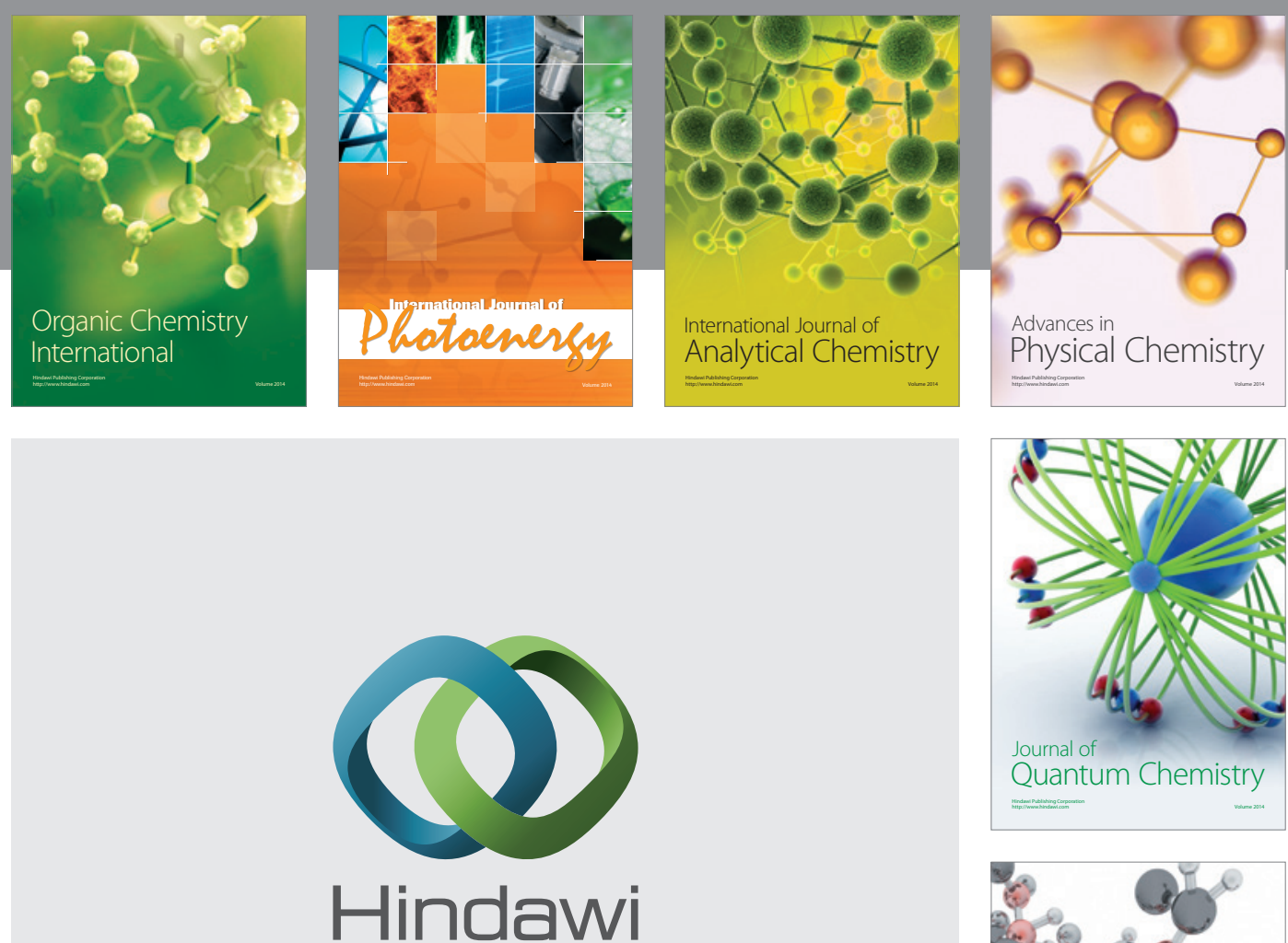

Submit your manuscripts at

http://www.hindawi.com

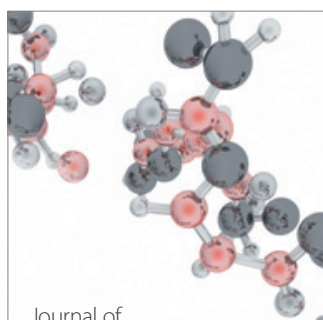

Analytical Methods

in Chemistry

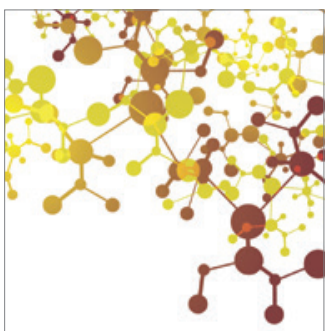

Journal of

Applied Chemistry

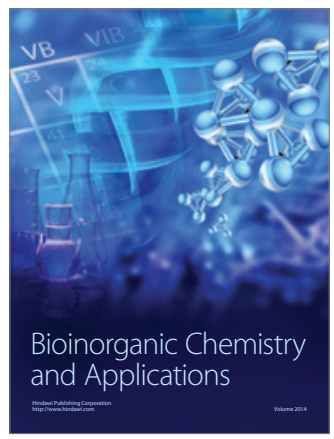

Inorganic Chemistry
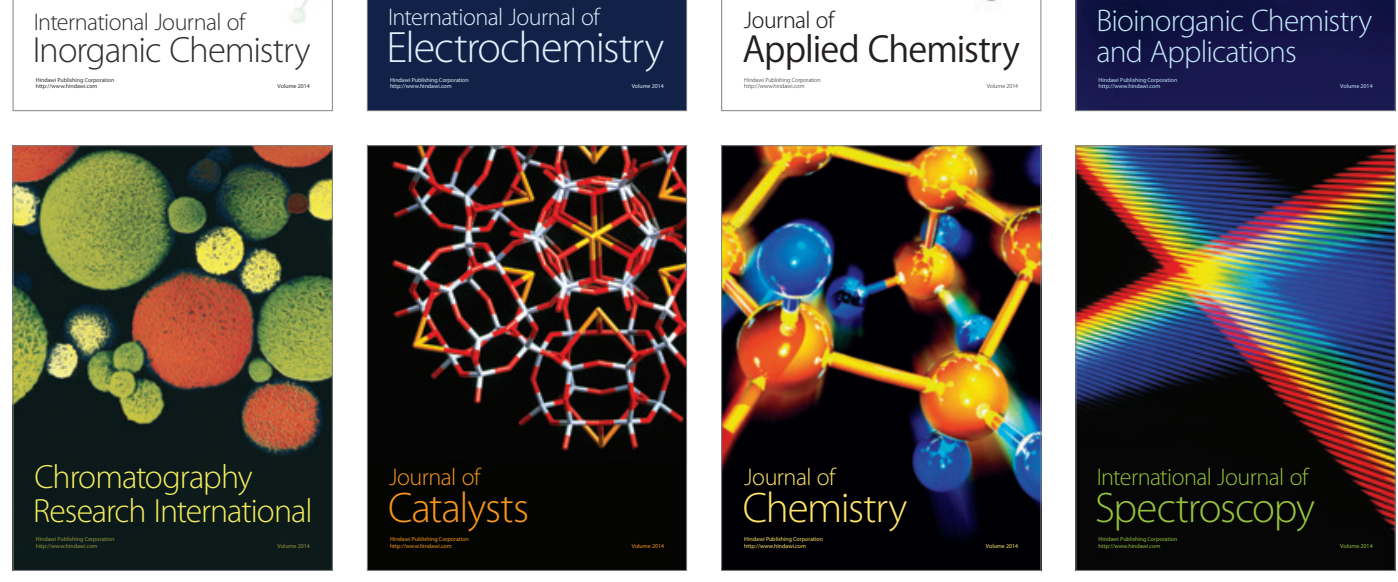